\title{
PERLINDUNGAN HUKUM TERHADAP KONSUMEN DALAM TRANSAKSI E- COMMERCE BERDASARKAN UNDANG-UNDANG NOMOR 11 TAHUN 2008 TENTANG INFORMASI DAN TRANSAKSI ELEKTRONIK BESERTA UNDANG- UNDANG NOMOR 8 TAHUN 1999 TENTANG PERLINDUNGAN KONSUMEN
}

\author{
Indah Puspa Sari \\ Fakultas Hukum Universitas Pamulang \\ indahpuspa@gmail.com
}

\begin{abstract}
E-commerce itself is a trade process that has its own characteristics where a trade that can cross the borders of the State, not even meeting between seller and buyer, using the internet as a facilitator. The situation is in one way quite beneficial to the consumer, because kaerena have many ways diplih to get the goods or services but viewed from the other side we see many rights violations as consumers that occur in e-commerce that does have its own characteristics. Therefore, the form of legal protection against consumers in $e$ commerce transactions is necessary. Legal protection for business actor either seller of service or consumer goods is also regulated in Law Number 8 Year 1999 About Consumer Protection and wrapping process of happening it in cyberspace transaction we call $e$ commerce have rules also that is in Law Number 11 Year 2008 About Information and Electronic Transactions. The methodology in this study using normative but the author adds a little approach through empirical to the normative self-author discussed based on the law applied directly to the general public. Based on these matters the authors conclude that first, Law number 8 of 1999 and Act number 11 of 2008 can protect and give the rules of the game in the world of online business clearly. Secondly, can manage from the consumer side or the perpetrator business.
\end{abstract}

Keywords: Consumer Protection, Information and Electronic.

\begin{abstract}
ABSTRAK
E-commerce itu sendiri merupakan suatu proses perdagangan yang memiliki karakteristik sendiri dimana suatu perdagangan yang dapat melintasi batas Negara, bahkan tidak bertemunya antara sipenjual dan pembeli, dengan menggunakan media internet sebagai fasilitator. Situasi tersebut dalam satu sisi cukup menguntungkan pihak konsumen,kaerena memiliki banyak cara yang diplih untuk mendapatkan barang atau jasa akan tetapi dilihat dari sisi lain banyak kita lihat pelanggaran hak sebagai konsumen yang terjadi dalam $e$ commerce yang memang mempunyai karakteristik tersendiri. Oleh karena itu bentuk perlindungan hukum terhadap konsumen dalam transaksi $e$-commerce sangat diperlukan. Perlindungan hukum pada pelaku bisnis baik penjual jasa atau barang juga konsumen diatur dalam Undang - Undang Nomor 8 Tahun 1999 Tentang Perlindungan Konsumen dan pembungkus proses terjadinya hal tersebut dalam transaksi dunia maya kita sebut $e$ commerce memiliki aturan juga yaitu dalam Undang - Undang Nomor 11 Tahun 2008 Tentang Informasi dan Transaksi Elektronik. Metodologi dalam penelitian ini menggunakan normative, untuk normatif sendiri hal ini dibahas berdasarkan undang-undang yang diaplikasikan langsung kepada masyarakat umum. Berdasarkan hal - hal tersebut dapat disimpulkan bahwa pertama,Undang-undang nomor 8 tahun 1999 dan Undang-undang nomor 11 tahun 2008 dapat melindungi dan meberikan aturan main dalam dunia bisnis online secara gamblang. kedua, dapat mengatur dari sisi konsumen maupun pelaku bisnis.
\end{abstract}

Kata Kunci: Perlindungan Konsumen, Informasi dan Transaksi Elektronik. 


\section{PENDAHULUAN}

Bentuk usaha masyarakat dalam proses perkembangan zaman yang sangat pesat saat ini banyak kita jumpai adanya berbagai bentuk usaha-usaha yang unik untuk memenuhi segala kebutuhan hidup. Salah satunya yang saat ini berkembang pesat dan banyak kita jumpai adanya berbagai macam bentuk usaha-usaha online yang memang tidak bisa dipungkiri sudah masuk pada fase perkembangan teknologi yang berbasis tinggi atau lebih dikenal "internet" yang juga biasa dikenal dengan nama e-commerce. E-commerce adalah elektronik commerce, merupakan kumpulan teknologi aplikasi dan bisnis yang menghubungkan perusahaan atau perseorangan sebagai konsumen untuk melakukan transaksi elektronik,pertukaran barang, dan pertukan informasi melalui internet atau televisi, website atau jaringan computer lainnya. E-commerce pada era globalisasi ini merupakan bentuk perdagangan yang sangat digemari masyarakat yang sangat penuh dengan kesibukan diberbagai bidangnya masingmasing yang menuntut pada masyarakat untuk tetap kerja, kerja dan kerja.

E-commerce pada prinsipnya merupakan bisnis dengan kegiatan bisnis tanpa warkat (paperless trading). ecommerce juga sering diartikan sebagai suatu transaksi jual beli atas suatu produk barang, jasa atau informasi antar mitra bisnis dengan memakai jaringan computer yang berbasiskan kepada internet. Suatu kegiatan e-ommerce dilakukan dengan orientasi-orientasi sebagai berikut:

1. Pembelian on line (on-line transaction)

2. Komunikasi digital (digital communication), yaitu suatu komunikasi secara elektronik.

3. Penyediaan jasa (service), yang menyediakan informasi tentang kualitas produk dan informasi instan terkini.
4. Proses bisnis, yang merupakan sistem dengan sasaran untuk meningkatkan otomatisasi proses bisnis.

5. Market of one, yang memungkinkan proses customization produk dan jasa untuk diadaptasikan pada kebutuhan bisnis.

Berdasarkan hal tersebut kita dapat meninjau dari sudut para pihak dalam bisnis e-commerce, maka yang merupakan jenis-jenis transaksi dari suatu kegiatan $e$ commerce adalah sebagai berikut:

1. Business to business (B2B)

2. Business to consumer $(B 2 C)$

3. Consumer to consumer $\left(\mathrm{C}_{2} \mathrm{C}\right)$

4. Consumer to business ( $\mathrm{C} 2 \mathrm{~B}$ )

5. Non-Business electronic commerce.

6. Intrabusiness (Organizational) Electronic commerce. (Fuady, 2016 : 408)

Internet adalah sebuah alat penyebar informasi secara global, sebuah mekanisme penyebaran informasi dan sebuah media untuk berkolaborasi dan berinteraksi antar individu dengan menggunakan computer tanpa terhalang batas geografis. Bahkan ada yang berpendapat bahwasanya internet itu merupakan investasi,dedikasi dan komitmen untuk sebuah riset dan pengembangan infrastruktur informasi. (Ustadiyanto, $2001:$ 1) Berdasarkan adanya internet maka menimbulkan bisnis-bisnis secara on line atau yang dijajakan melalui internet. Contohnya seperti berbagai macam on line shop yang menawarkan barang atau jasa. Dari hal tersebut kita dapat mengetahui adanya perjalanan atau pertumbuhan e-commerce diindonesia. Sistem pembayaran ini menggunakan crypthography dalam pelaksanaanya sehingga dapat menjamin keamanan transaksi lewat internet (internet secure transaction) antara lain adalah GTE Cybertrust, IBM, Netscapa, SAIC, Terisa System dan juga Verisgn Inc. (Ustadiyanto, Framework E-commerce, cetakan 1, 2004 : 13) 
Berdasarkan Tabel Pertumbuhan $\mathrm{B} 2 \mathrm{C} e$ commerce (Ustadiyanto, Framework Ecommerce, cetakan 1, 2004 : 13)disimpulkan bahwa nilai transaksi $e$ commerce masih sangat kecil dibandingan dengan nilai transaksi di dunia. Oleh karena itu penulis banyak mengambil kasus buruknya bisnis on line di Indonesia dalam berbagai bidang pemberdayaan transaksi $e$ commerce tersebut. Namun hal ini tidak bisa dipungkiri dengan banyaknya masalahmasalah hukum dalam transaksi $e$ commerce tersebut. Secara umum David Baum, yang dikutip oleh Onno W.Purbo dan Aang Arif Wahyudi. (Wahyudi, 2001 : 1-2)

"E-commerce is a dynamic set of technologies, application, and business process that link enterprieses, consumer and communication through electronic transactions and electronic exchange of goods,service and information". E- commerce merupakan satu set dinamis teknologi, aplikasi dan proses bisnis yang menghubungkan

perusahaan,konsumen dan komuniutas tertentu melalui transaksi elektronik dan perdagangan barang, jasa, dan informasi yang dilakukan secara elektronik.”

Association for electronic commerce secara sederhana mendefinisikan $e$ commerce sebagai mekanisme bisnis secara elektronis. CommerceNet, sebuah kosorsium industry memberikan definisi lengkap yaitu penggunaan jaringan computer sebagai sarana penciptaan relasi bisnis. Tidak puas dengan definisi tersebut CommerceNet menambahkan bahwa di dalam e-commerce terjadi proses pembelian dan penjualan jasa atau produk antara dua belah pihak melalui internet atau pertukaran dan distribusi informasi antar dua belah pihak dalam satu perusahaan dengan menggunakan internet. Menurut ECEG-Australia (Electronic Commerce Expert Group) " Electronic commerce is a board concept that covers any commercial transaction that is effeted via electronic means and would include such means as facsimile, telex, EDI, internet and telephone. (Indrajie, 2001:3) Berdasarkan perngertian tersebut,ecommerce meliputi transaksi perdagangan melalui media elektronik. Dalam arti kata tidak hanya media internet yang dimaksud, tetapi juga meliputi semua transaksi perdagangan melalui media elektronik lainnya seperti faxsimile, telex, EDI dan telephone.

Dari karakteristik tersebut terlihat jelas bahwa pada dasarnya e-commerce merupakan dampak dari perkembangan teknologi informasi dan telekomunikasi, dan secara signifikan mengubah cara melakukan interaksi dengan lingkungan,yang dalam hal ini terkait dengan mekanisme dagang yang dewasa ini sedang digandrungi oleh berbagai kalangan baik tua,dewasa maupun anak-anak. Transaksi jual beli melalui $e$-commerce, biasanya akan didahului oleh penawaran jual,penawaran beli dan penerimaan jual atau melalui posting di mailing list dan newsgroup atau melalui undangan untuk para customer melalui model business to businesss. (Pramono, 2001 : 16) Berbelanja dengan menggunakan order form merupakan salah satu cara berbelanja yang paling sering digunakan dalam $e$ commerce. Dengan cara ini merchant menyediakan daftar katalog barang (product table) yang dijual. Saat tahap order dilaksanakan, biasanya produk yang dijual tidak divisualisasikan dalam bentuk gambar ,akan tetapi dalam bentuk deskripsi produk. Dalam sebuah halaman order form, sesi penawaran produk terbagi menjadi empat bagian, yaitu:

1. Chek box yang dibuat untuk memberi kesempatan kepada customer untuk memiliki produk yang ditawarkan dengan mengeklik kotak tersebut hingga bertanda chek.

2. Penjelasan produk yang ditawarkan. 
3. Kuantitas barang yang dipesan.

4. Harga untuk tiap - tiap produk.

Bagi masyarakat yang awan akan teknologi mungkin terlalu rumit seperti ibuibu yang terbiasa berbelanja ke pasar-pasar tradisional maupun supermarket apalagi tidak begitu terjamin bentuk dan warna barang yang kita pesan sesuai harapan kita, oleh karena itu perlu adanya badan yang khusus bergerak melayani, mengayomi dan membantu arahan transaksi $e$-commerce yang dapat menjadi payung hukum sekaligus.

\section{METODE PENELITIAN}

Penelitian hukum merupakan suatu kegiatan ilmiah yang didasarkan pada metode, sistematika dan pemikiran tertentu yang bertujuan untuk mempelajari satu atau beberapa gejala hukum tertentu dengan jalan menganalisanya. Karena itu maka perlu juga diadakan pemeriksaan mendalam terhadap perundang-undangan, teori-teori hukum serta dapat pula melakukan pengumpulan data hukum kepada sarjana-sarjana hukum terkemuka maupun para praktisi-praktisi hukum yang berpengalaman dibidangnya masingmasing. Penulis Menggunakan data yang meliputi sumber Data Primer merupakan bahan hukum yang dapat mengikat sifatnya, yang terdiri dari peraturan perundang-undangan yang terkait dengan transaksi e-commerce atau bisnis on line. Sumber Data Sekunder

merupakan bahan hukum yang menjelaskan tentang bahan hukum primer,antara lain buku-buku yang yang berkaitan dengan transaksi $e$-commerce atau bisnis on line. Sumber Tertier merupakan bahan hukum yang bahanbahannya didapat untuk memperjelas suatu persoalan atau suatu istilah yang ditemukan pada bahan-bahan hukum premier dan sekunder, yang terdiri dari kamus hukum, kamus bahasa dan dokumen tertulis. Bahan hukum yang telah diperoleh, diinventarisir dan diidentifikasi untuk digunakan sebagai bahan dalam menganalisa permasalahanpermasalahan dalam penulisan ini. Identifikasi bahan hukum baik yang secara primer maupun sekunder harus dilakukan secara kritis, logis dan sistematis yang sesuai dengan tatanan atau aturan hukumhukum yang berlaku di dalam metode penelitian hukum ini atau dalam penulisan tesis ini agar sesuai dengan kode etik yang berlaku.

\section{PERMASALAHAN}

Adapun perumusan masalah dalam penelitian ini adalah Apakah UndangUndang Nomor 8 Tahun 1999 Tentang perlindungan Konsumen dan UndangUndang nomor 11 tahun 2008 Tentang Informasi dan Transaksi Elektronik dapat melindungi konsumen dalam melakukan transaksi e-commerce Selanjutnya dalam masalah apa yang timbul dalam transaksi $e$ commerce terkait perlindungan konsumen bagaimana mengatasi hal tersebut?

\section{PEMBAHASAN}

\section{Tinjauan Umum Tentang Transaksi E-Commerce}

Pengertian transaksi e-commerce secara umum yaitu suatu transaksi jual beli atas suatu produk barang, jasa atau informasi antarmitra bisnis dengan memakai jaringan computer yang berbasiskan kepada internet. Berdasarkan pasal 1 ayat (17) rancangan undang-undang tentang pemanfaatan teknologi informasi, "kontrak elektronik adalah perjanjian yang dimuat dalam dokumen elektronik yang dituangkan dengan kontrak elektronik mengikat dan memiliki kekuatan hukum sebagai suatu perikatan”. Dari pengertian diatas, dapat disimpulkan bahwa perjanjian secara elektronik adalah kesepakatan antara kedua belah pihak yang dilakukan secara elektronik, dimana para pihak dalam melaksanakan perjanjian tidak memerlukan tatap muka secara langsung. 
Persoalan transaksi e-commerce sangatlah berkaitan dengan perjanjian hal ini berkenaan dengan banyak digunkannya perjanjian baku didunia bisnis,maka sudah sepatutnya kita menetukan perjanjian apakah yang baku untuk hukum perjanjiaan dalam transaksi e-commerce. Biasanya dalam mengenai pencamtuman klausal eksenorasi. Klausal eksenorasi adalah syarat yang secara khusus membebaskan pengusaha dari tanggung jawab terhadap akibat yang merugikan yang timbul dari pelaksanaan perjanjian. Menurut Abdulkadir Muhammad, klausala eksenorasi mempunyai tujuan utama yaitu mencegah pihak konsomen merugikan kepentingan pengusaha karena dalam hubungan ekonomi dikatakan bahwa pembeli adalah raja, sebagai raja konsumen dapat berbuat semaunya sehingga merugikan pengusaha. Pengusaha mencoba menghindari kemungkinan timbulnya kerugian dengan menciptakan syarat baku yang disebut eksenorasi (Muhammad, 1992 :20).

E-commerce juga merupakan dampak dari perkembangan teknologi adapun beberapa cara transaksi dalam e-commerce yaitu:

1. Pertama melalui penawaran jual beli dan penerimaan jual beli secara online, contohnya: melalui website situs di internet atau posting di mailing list dan newsgroup dan bisa juga menggunakan undangan untuk para customer melalui model business to business.

2. Kedua melalui transaksi dengan menggunakan email,dalam hal ini baik penjual maupun pembli harus memliki email addres masing-masing agar mempermudah proses pembelian barang atau jasa serta dalam menentukan cara pembayaran yang ingin digunakan para pihak (Komputer, 2001 : 63).

3. Ketiga melalui transaksi chatting atau video conference yaitu dengan cara menawarkan sesuatu menggunakan model dialog interaksi melalui internet,seperti melalui handphone, video converence semuanya melalui elektronik,mereka dapat bertatap muka langsung gambar dan mendengar suara antara penjual dan pembeli.

4. Keempat melalui transaksi web atau cara merchant yang menyediakan katalog barang yang dilengkapi deskripsi produk yang dijual oleh sang penjual produk.istilahnya disebut dengan order form dan shopping cart.

\section{Penerapan Prinsip-Prinsip Hukum Dalam Bisnis E-Commerce Terhadap Perlindungan Konsumen}

Hukum konsumen dalam bentuk hukum perdata dimaksudkan dalam arti yang luas yaitu termasuk dalam hukum perdata, hukum dagang beserta kaidahkaidah keperdataan yang termuat didalam peraturan perundang-undangan lainya, baik hukum perdata tertulis maupun tidak tertulis. (Nasution, 1999 : 38) Hukum konsumen dalam bentuk hukum publik hal ini dimaksudkan berupa hukum yang mengatur hubungan antara Negara dan alat-alat perlengkapanya atau berupa hubungan Negara dengan perorangan. Merupakan hukum publik terutama dalam kerangka hukum konsumen dan perlindungan konsumen yaitu hukum pidana, hukum acara perdata, kukum acara pidana dan hukum Internasional terutama hukum perdata internasional.

Dalam bisnis e-commerce banyak produk-produk yang ditawarkan melalui internet mulai dari obat tradisional sampai barang-barang mewah, mulai dari informasi penjualan baju-baju bekas hingga baju bermerek seperti Calvin klein, kenzo, dan sebagainya serta mulai dari sepatu produksi cibaduyut hingga merek-merek terkenal produksi italia. Semua tersaji menarik dalam internet, kondisi ini merupakan salah satu alasan konsumen lebih menyukai belanja melalui internet. Menurut Johanes Gunawan, perlindungan hukum terhadap konsumen dapat dilakukan pada 
saat sebelum terjadinya transaksi (no conflict/purchase) dan pada saat setelah terjadinya transaksi (conflict/post purchase) (Gunawan, Hukum Perlindungan Konsumen, 1999 : 3).

Hak konsumen menurut pasal 4 undang-undang perlindungan konsumen, adalah:

1. Hak atas kenyamanan, keamanan dan keselamatan dalam mengkonsumsi barang dan/atau jasa.

2. Hak untuk memilih barang dan/atau jasa serta mendapatkan barang dan/atau jasa tersebut sesuai dengan nilai tukar dan kondisi serta jaminan yang dijanjikan.

3. Ha katas informasi yang benar, jelas, dan jujur mengenai kondisi dan jaminan barang dan/atau jasa.

4. Hak untuk didengar pendapat dan keluhanya atas barang dan/atau jasa yang digunakan.

5. Hak untuk mendapat advokasi perlindungan, dan upaya penyelesaian sengketa perlindungan konsumen secara patut.

6. Hak untuk mendapat pembinaan dan pendidikan konsumen.

7. Hak untuk diperlakukan atau dilayani dengan benar dan jujur serta tidak diskriminatif.

8. Hak untuk mendapat konpensasi, banti rugi dan/atau penggantian, apabila barang dan/atau jasa yang diterima tidak dengan perjanjian atau tidak sebagaimana mestinya.

9. Hak-hak yang diatur dalam ketentuan peraturan perundang-undangan laianya.

\section{Perlindungan Konsumen Dalam Transaksi E-Commerce Di Indonesia}

Sistem keamanan dalam dunia computer mulai menjadi perhatian serius para penelitidan praktisi teknologi informasi sejak ditemukanya teknologi jaringan computer. Pemicu berkembangnya isu dibidang ini adalah karena adanya fenomena pengiriman data melalui media tranmisi (darat, laut dan udara)yang mudang "dicuri" oleh mereka yang tidak berhak. Data mentah dari sebuah computer yang dikirim ke computer lain pada dasarnya rawan terhadap "intervensi" pihak ketiga,sehingga diperlukansuatu strategi khusus agar terjadi, paling tidak ada dua hal: (Indrajit, $2001: 83$ )

1. Data yang dikirimkan tidak secara "fisik" diambil oleh pihak lain yang tidak berhak; atau

2. Data yang dikirimkan dapat "diambil secara fisik", namun yang bersangkutan tidak dapat membacanya.

Information cecurity yang dapat diterima di dalam e-commerce mutlak dibutuhkan. Di era internet, semua kebutuhan dan keinginan sedapat mungkin diterima dengan cepat, mudah dan aman. Untuk itulah peranan teknologi keamanan informasi bener-bener dibutuhkan (Wahyudi O. W., 2001 : 17). Sistem keamanan informasi memiliki empat macam tujuan yang sangat mendasar, yaitu:

1. Confidentiality

Menjamin apakah informasi yang dikirim tersebut tidak dapat dibuka atau tidak sapat diketahui oleh orang lain yang tidak berhak. Terutama untuk data yang teramat penting, dibutuhkan tingkat kerahasiaan yang sangat tinggi, yang hanya bisa diakses oleh orangorang tertentu saja (orang-orang yang berhak) yang memiliki sangkutan atau hubungan dalam hal atau urusan akses tersebut,demi suatu bentuk nyata dalam ilmu kerahasian yang terbentuk dalam akses sistem tersebut.

\section{Integrity}

Menjamin konsistensi dan keutuhan data sesuai dengan aslinya, sehingga upaya orang-orang yang tidak bertanggungjawab untuk melakukan penduplikatan dan perusakan data bisa dihindari.

\section{Availability}

Menjamin pengguna yang sah agar bisa mengakses informasi dan sumber 
miliknya sendiri. Tujuanya adalah untuk memastikan bahwa orang-orang yang memang berhak tidak ditolak untuk mengakses informasi yang memang menjadi haknya.

\section{Legitimate use}

Menjamin kepastian bahwa sumber tidak digunakan (informasi tidak diakses) oleh orng-orang yang tidak bertanggung jawab (orang-orang yang tidak berhak).

Pada saat ini banyak metode yang dapat dipakai untuk pembayaran transaksi e-commerce. Dalam transaksi e-commerce pembayaran dilakukan secara sedikit berbeda, biasanya dalam transaksi ini pembayaran lazimnya dilakukan secara elektronik, yaitu:

1. Pembayaran dengan kartu kredit/kartu debit.

Dalam dunia kartu kredit/kartu debit ada beberapa pihak yang berperan dalam transaksi e-commerce. Pemegang kartu kredit/kartu debit disebut dengan istilah cardholder. Kartu kredit/kartu debit diterbitkan oleh sebuah bank, yang biasa disebut issuer. Bank-bank tersebut melakukan licensee merek kartu kredit/kartu debit dari institusi kartu kredit/kartu debit seperti Visa, Mastercard atau Maestro. Selanjutnya pedagang (merchant) yang dapat menerima kartu kredit/kartu debit juga memiliki hubungan dengan sebuah bank, yang dikenal dengan istilah acquirer. Pada acquirer inilah merchant memiliki account yang akan "menampung" uang dari cardholder.

2. Pembayaran dengan $e$-Check

E-Check atau electronic check merupakan salah satu metode pembayaran dalam transaksi ecommerce. Dalam pembayaran dengan $e$-Check, pertama tama konsumen membuka account bank di internet untuk pertama kali. Kemudian konsumen mengeluarkan e-check miliknya untuk membayar. Penerima $e$ check ini mengirimkan cek tersebut ke bank untuk konfirmasi bahwa transaksi tersebut bener-bener valid, akhirnya bank memindahkan uang dari rekening pengirim ke rekening penerima cek sesuai dengan nilai yang tercantum.

3. Pembayaran dengan Digital Cash

Digital cash memiliki karakteristik utama, yaitu transnationality of digital cash, dimana digital cash memilki kemampuan mengalir secara bebas melewati batas hukum Negara lain. Karakteristik inilah yang menjadi sumber kelebihan dan kekurangan digital cash. Di satu sisi, digital cash menjadi lebih efisien, tidak berbelit-belit, di sisi lain hal ini dapat menimbulkan pertentangan antara prinsip kebebasan cyberspace dengan hukum suatu Negara (Wahyudi O. W., Mengenal e-Commerce , 2001:25-126).

\section{Pengaturan hukum dalam melakukan transaksi e-commerce}

Hukum di Indonesia belum memiliki pengaturan yang jelas mengenai transaksi e-commerce, maka dari itu penulis merujuk pada pengaturan perjanjian jual beli secara konvensional yang ada dalam KUH perdata untuk menghaji transaksi e-commerce. Menurut Mieke Komar Kantaatmadja perjanjian jual beli yang dilakukan melalui media elektronik internet tidak lain adalah merupakan perluasan dari konseo perjanjian jual beli yang ada dalam KUH Perdata. Perjanjian jual beli melalui internet ini memiliki dasar hukum perdagangan konvensional atau jual beli dalam hukum perdata. Perbedaanya adalah bahwa perjanjian melalui internet ni bersifat khusus karena terdapat unsur peranan yang sangat dominan dari media dan alat-alat elektronik.

Menurut pasal $1457 \mathrm{KUH}$ Perdata jual-beli adalah suatu persetujuan dengan mana pihak yang satu mengikatkan dirinya untuk menyerahkan suatu barang, dan 
pihak yang lain untuk membayar harga yang dijanjikan. Unsur-unsur pokok (essentiallia) perjanjian jual beli adalah barang dan harga. Sesuai dengan asas Konsensualisme yang menjiwai perjanjian dalam KUH Perdata, perjanjian jaul beli itu sudah dilahirkan pada detik tercapainya "sepakat" mengenai barang dan harga. Begitu kedua belah pihak setuju dengan barang dan harga, maka lahirlah perjanjian jual beli yang sah. Sifat konsensual dari jual beli menurut Pasal 1458 berbunyi "Jual beli dianggap sudah terjadi antara kedua belah pihak seketika setelah mereka mencapai sepakat tentang barang dan harga, meskipun barang itu belum diserahkan maupun harganya belum dibayar”. Jadi dapat disimpulkan bahwa dengan disebutkannya kata "sepakat" saja tanpa harus membuat suatu tulisan, akta dan lain sebagainya, maka suatu perjanjian telah lahir secara sah atau mengikat para pihak yang membuatnya dan berlaku sebagai Undang - undang bagi mereka yang membuatnya.

\section{PENUTUP}

\section{Kesimpulan}

Bentuk perlindungan hukum terhadap konsumen dalam transaksi e-commerce telah disesuaikan dengan undang-undang perlindungan konsumen Nomor 8 Tahun 1999 (Tentang Perlindungan Konsumen) Serta diterapkan sesuai peraturan yang diatur dalam proses transaksi e-commerce tersebut, yang mana telah diatur dalam beberapa pasal dan perundang-undangan yang terdapat pada Undang - undang Nomor 11 Tahun 2008 tentang Informasi dan Transaksi Elektronik.

Kedua undang-undang tersebut dapat mengatur adanya berbagai bentuk transaksi-transaksi e-commerce antara pihak penjual dan pembeli atau pelaku usaha dan konsumen, berdasarkan perjanjian-perjanjian tertentu yang sesuai peraturan perundang-undangan tersebut.
Masalah - masalah yang dihadapi dalam transaksi $e$-commerce yaitu adanya suatu konflik dalam hubungan antara konsumen akhir dengan pelaku usaha yang belum maksimal menyajikan fasilitas dalam transaksi online atau bisnis e-commerce, hal ini diawali tidak adanya kepercayaan berupa jenis perjanjian yang digunakan dalam transaksi e-commerce ini. Dalam transaksi e-commerce ini hanya menggunakan transaksi dalam perjanjian dengan semua fasilitas digital termasuk tanda tangan, namun masaalah tersebut dapat diatasi dengan adanya penguat bentuk-bentuk transaksi online yaitu dengan diaturnya segala urusan mulai dari perlindungan konsumen yang semuanya termasuk dalam Undang-undang perlindungan konsumen Nomor 8 Tahun 1999 dan bentuk-bentuk fasilitas online yang dikuatkan dengan kekuatan hukum sebagai bukti-buktinya, salah satunya adanya perjanjian jual beli secara online yang dilindungi oleh undang-undang informasi dan transaksi elektronik, karena semuanya telah mencukup kebutuhan dalam bertransaksi online, maka masalah masalah yang terjadi dalam bisnis $e$ commerce dapat diatasi dengan baik dan benar guna membantu menghindari permasalahan hukum yang dihadapi dikemudian hari baik masalah yang timbul berdasarkan kesengajaan pelaku bisnis ataupun konsumen.

\section{Saran}

Untuk dapat lebih memberi kepastian hukum dalam transaksi e-commerce sebaiknya selalu diterangkan dengan jelas dalam bentuk transaksi online baik barang maupun jasa tentang klausula yang mengatur tentang perlindungan konsumen dan memberitahukan batasan-batasan untuk konsumen sebagai pembeli barang atau pengguna jasa online tentang kejelasan status hukum jual beli yang dilakukan dalam bentuk apapun baik dalam status hukum sebagai penjual atau pelaku 
bisnis tersebut atau kita sebagai konsumen itu sendiri agar tercapai suatu sistem bentuk kepastian hukum yang merata adil dan makmur sesuai falsafah dalam undang - undang dan ideology pancasila yang berlaku sebagai acuan hukum di Negara kita. Dalam hal ini pemerintah seharausnya dapat membeikan perlindungan hukum dibatas "konsumen akhir" yang menurut undang - undang tersebut ataupun "konsumen antara" sesuai peraturan perundang-undangan yang ada sekalipun sudah melalui batas wilayah Indonesia atau Negara karena sudah pasti untuk bicara bisnis e-commerce maka merupakan bisnis yang mengglobal diseluruh dunia dan sudah seharusnya pemerintah memberikan dukungan atas kemajuan zaman pada masa ini dimana segalanya hamper mengunakan fasilitas online atau yang serba online ini dengan memperkuat tatanan hukum perundang-undangan yang mengatur transaksi online tersebut.

Baik pihak konsumen atau pun pelaku usaha yang baik berupa pelaku usaha berupa jasa maupun barang - barang hal ini agar dapat lebih memberikan rasa nyaman pada keduanya yaitu pelaku usaha tersebut maupun konsumen tersebut karena pada dasarnya masyarakat berkeinginan untuk memajukan juga kesejahteraan masyarakat salah satunya dengan mengaplikasikan layanan serba online dengan majunya pola piker masyarakat dalam berbisnis maka merupakan babak awal proses kemajuan zaman yang sangat pesat mulai dari sekarang hingga dimasa yang akan datang kelak nanti.

\section{DAFTAR PUSTAKA}

A. Qiram Syamsudin Meliala, Pokok-pokok Hukum Perjanjian Beserta Perkembanganya, (Yogyakarta, Liberty, 1985).

Abdul Hakim Berkatullah dan Teguh Prasetyo, Bisnis E-Commerce, (Yogyakarta, Pustaka Pelajar, 2005).
Abdul Kadir Muhammad,Hukum Perikatan, (Bandung, Citra Aditya Bakti, 1992).

Abdul R. Saliman, Hukum Bisnis Untuk Perusahaan, Teori dan Contoh Kasus, (Jakarta, Prenada Media Group, 2005).

Abu Bakar Munir, Cyber Law, Policies and Challenges, (Butterworths Asia, 1999).

Ade Maman Suherman, Aspek Hukum Dalam Ekonomi Global, (Jakarta, Ghalia Indonesia, 2002).

Anggraeni, Hukum Perikatan, Perikatan yang Lahir dari Perjanjian, (Semarang, Badan Penerbit Undip, 2003).

Az. Nasution, Konsumen dan Hukum, (Jakarta: Pustaka Sinar Harapan, 1995).

Bagus Hanindyo Mantri "Perlindungan Hukum Terhadap Konsumen Dalam Transaksi E-commerce" (Tesis Fakultas Hukum Universitas Diponegoro Semarang).

Buchari Alma, Kewirausahaan, (Bandung, Alfabeta, 2011).

Budi Agus Riswandi, Hukum dan Internet di Indonesia, (Yogyakarta, UII Press, 2003).

David Kosiur, Understanding Electronic Commerce, (Washington, Microsoft Press, 1997).

Dikdik M. Arief Mansur dan Elisatris Gultom, Cyber Law (Aspek Hukum

Edmond Makarim, Kompilasi Hukum Telematika, (Jakarta, PT. Raja Grafindo Persada, 2003).

Elisatris Gultom, Perlindungan Konsumen Dalam Transaksi ECommerce, Dalam Cyber Law, Suatu Pengantar, (Bandung, Elips, 2002).

Frans Satriyo Wicaksono, Membuat Suratsurat Kontrak, (Malang, Visimedia, 2009).

Gunawan Widjaja dan Ahmad Yani, Hukum Tentang Perlindungan Konsumen, 
(Jakarta: PT. Gramedia Pustaka Utama, 2000).

Haris Faulidi Asnawi, Transaksi Bisnis ECommerce Perspektif Islam, (Yogyakarta, Magistra Insania Press, 2004).

http://www.tempo.co.id/, diakses 15 Mei 2018 Pukul 10.25 WIB.

I. Arif Priharsanta, Implementasi Prototipe Proses Otoritas Kartu Pembayaran Antara Merchant dan Payament Gateway Pada Protokol Secure Electrini Transaction, Skripsi, Depok, Universitas Indonesia.

Imam Budi Setiawan, Smartwallet-java Wallet Berbasis Smartcard Dan Protokol Set, Skripsi Depok Universitas Indonesia.

Indonesia, Undang - undang nomor 11 tahun 2008 Tentang Informasi dan Transaksi Elektronik.

Indonesia, Undang - undang nomor 8 tahun 1999 tentang perlindungan konsumen.

Johanes Gunawan, Hukum Perlindungan Konsumen, (Bandung, Universitas Katolik Parahyangan, 1999).

Maftuhah, A. Sigit Suryanto, Lisa Esti, Undang-undang ITE (Informasi dan Transaksi Elektronik), (Yogyakarta, New Merah Putih, 2009).

Mariam Darus Badrulzaman dkk, Kompilasi Hukum Perikatan, (Bandung, PT. Citra Aditya Bakti, 2002).

Munir Fuady, Hukum Bisnis, (Bandung, PT. Citra Aditya Bakti, 2016).

Onno W. Purbo dan Aang Arif Wahyudi, Mengenal e-Commerce, (Jakarta, Elex Media Komputindo, 2001).

Otje Salman, Teori Hukum, (Bandung, PT. Refika Aditama, 2013).

Perpres Nomor 50 Tahun 2017 Tentang Strategi Nasional Perlindungan Konsumen.
Perpres nomor 50 tahun 2017 Tentang Strategi Nasional Perlindungan Konsumen.

Purwahid Patrik, Dasar-dasar hukum perikatan, Perikatan yang lahir dari perjanjian dan dari undangundnag, (Bandung, Mandar Maju, 1994).

Richard Burton Simatupang, Aspek Hukum dalam Bisnis, (Jakarta, Rineka Cipta, 2011).

Richardus Eko Indrajit, E-Commerce: Kiat dan Strategi Bisnis di Dunia Maya, (Jakarta, PT. Elex Media Komputindo, 2001).

Riyeke Ustadiyanto, Framework $e$ Commere, (Yogyakarta, Andi, 2001).

SEMA RI Tanggal 5 September 1963 Tentang Gagasan Menganggap BW tidak sebagai Undang-undang dalam Az. Nasution,Hukum Perlindungan Konsumen Suatu Pengantar, (Jakarta, Daya Widya, 1999).

SEMA RI Tanggal 5 September 1963 Tentang Gagasan menganggap BW Tidak sebagai undang - undang dalam Az. Nasution, Hukum perlindungan konsumen suatu pengantar, (Jakarta, Daya Widya, 1999).

Subekti, Hukum Perjanjian, (Jakarta, PT. Intermasa, 2010).

Sutan Remy Sjahdeini, Kebebasan berkontrak dan perlindungan yang seimbang bagi para pihak dalam perjanjian kredit Bank di Indonesia, (Jakarta, Institut Bankir Indonesia, 1993).

Teknologi Informasi), (Bandung, Refika Aditama, 2005).

Tim litbang wahana Komputer,apa dan bagaimana e-commerce, (Yogyakarta, Andi, 2001).

www.baratamdia.com, diakses 3 Agustus 2018 Pukul 13.33 WIB.

Zoemrotin K. Susilo, Penyambung Lidah Konsumen, (Jakarta, Puspa Swara, 1996). 